\title{
The Design and Simulation for High-altitude Wind Power Generation System
}

\author{
Haowei Hu \\ School of energy power and mechanical engineering, North China Electric Power University, \\ Baoding 071003, China \\ farstreet@163.com
}

Keywords: wind energy, high-altitude wind power, numerical simulation.

\begin{abstract}
Today in the promotion of energy conservation, as a clean and renewable resource, wind energy is enjoying more and more attention in the world. To overcome the uncertainty and other limitations of wind, people began to take advantage of high-altitude wind energy. Currently high-altitude wind power technology has improved steadily and put into use gradually, so based on this development, in this paper a wind turbine is flied through the suspension to $300 \mathrm{~m}$ altitude by a balloon crust to achieve the greatest degree of wind energy; at the same time in order to efficiently generate electricity, the device also has a solar energy utilization device. Furthermore, by FLUENT software the inner flow field in the turbine has conducted a numerical simulation to verify the feasibility of the system.
\end{abstract}

\section{Introduction}

With non-renewable resources like coal and petroleum dying out, new energy is coming up to exploit its incomparable merits as a substituent to the traditional energy, gaining an increasing amount of attention. Among them, the wind energy is of great potential use.

Compared with other kinds of resources, wind energy has its typical strength in many ways. Clean as it is, on account that wind power is available locally, the electrical transporting way cuts down the cost of long distance transportation, which reduces the possibility of energy waste. Besides, wind is a resource that can be captured and applied regardless of the restriction of weather or position. Furthermore, as is known, water is a rich resource, while wind energy is almost ten times more than that.

However, due to complex terrain conditions, wind energy resources are not shared equally. With the uncertainty, regional and intermittent problems of wind, it has been faced with great restrictions.

\section{High-altitude wind power technology}

For problems occurring in wind energy applications, high-altitude wind power technology is coming into being. Studies have shown that the wind at an altitude of $2000-8000 \mathrm{~m}$ air is much stronger and more stable than the ground surface, on both sides of the equatorial latitudes near 30 degree in the region, with an average annual wind power density of up to $2.0 \mathrm{~kW} / \mathrm{m}^{2}$, which is suitable for wind power ${ }^{[1]}$.

As early as 2004, scientists in Netherlands have begun trying to manufacture a powerful kite which can fly at high altitude. After four years of attempts, in August 2008, this team succeeded in capturing energy from the air and produced $10 \mathrm{~kW}$ of electricity, for 10 families to use (Figure 1 (a)); In 2008, the Canadian company has developed a balloon-type machine, rising to the highest point from the ground. The fan drive, rotating mechanical energy into electrical energy through a generator, transformer to recharge the battery or directly enter the power grid (Figure 1 (b)); In 2007, Turin University manufactured a $20 \mathrm{~kW}$ prototype wind kite and is expected to build the power station in future (Figure 1 (c)) ${ }^{[2]}$. 


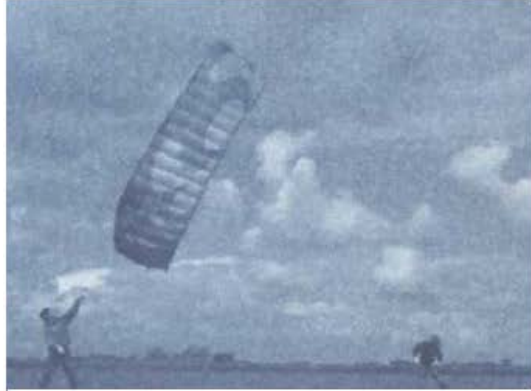

(a)

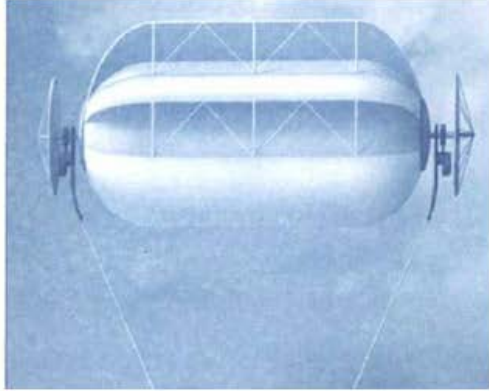

(b)

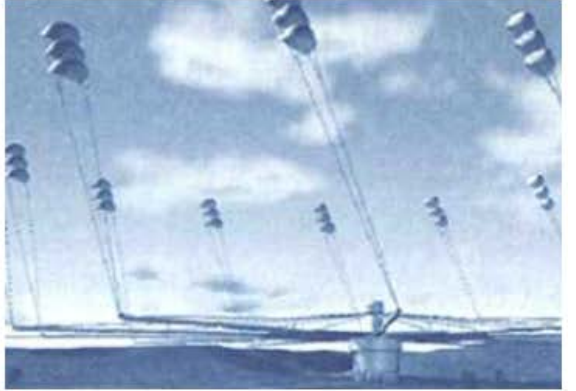

(c)

Fig. 1 Three wind turbine generators

The current vision for the high-altitude wind power is to produce a device through the use of high-altitude wind power - one is to build power plants in the air whose energy is generated by the power aerial cable supplied to the ground ; or first the generator deliver the mechanical energy to the ground, then convert the electrical energy. But because of the limited height of buildings in the ground, the available air flow is limited; secondly, taking into account the uncertainty of the wind, how to make high efficiency of power generation device has become one of the more difficult problems; and, due to the presence of low frequency noise, the area of its installation is also very limited.

\section{Floating wind generator system design}

\section{Theory design.}

Figure 2 illustrates the system of the generator architecture, which includes a suspension airbag shell, the core power part and the traction structure.
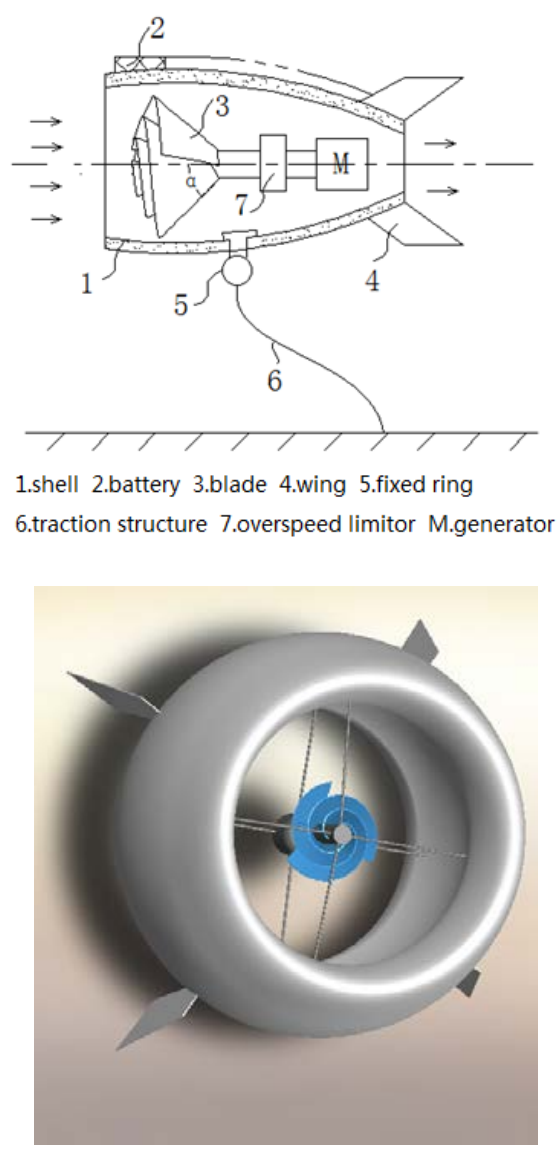

Fig. 2 Generator System 
Suspension airbag shell. For aerial power generation device, the shell must ensure adequate strength and have the ability to capture enough wind and solar energy. For the above reasons, the shell is designed to a tube-type structure - the inner tube is as the inlet pipe and the outer wall is mounted airbags.

The outer layer of the airbags is designed as tapered tube, while the tail is armed with wings to provide lifting strength. It's made of transparent special nylon, when not inflated, it can be compressed fold; when filled with helium inside, and it will ensure enough power to suspend in the air. When working at height, this special shape can make it always rotate to the direction of maximum wind speed for wind energy.

The core power part. The core power part includes wind power generator and solar power generator.

Wind power generator

Wind power generator is an axial wind turbine with spiral blades, the support shaft, the rotating shaft, overspeed limitor, the generator and voltage regulator tube. The spiral shape of blades is to overcome the resistance of the flow and to capture wind energy. In case that the speed is too fast to prevent the blades from overload, it also has rotating shaft at the rear with a restriction device to ensure the speed is less than $1200 \mathrm{r} / \mathrm{min}$; generator is used to form wind energy into electrical energy, then deliver it to the ground to storage.

Solar power generator. To further enhance the high-altitude power generation capacity and improve energy utilization, the device also has a solar power generator by the spread on a surface of the shell solar panels. Solar power generator includes solar panels, DC-DC boost chip and the regulator. The solar energy tackled by the DC-DC boost chip and the regulator is also delivered to the surface treated control energy storage through transmission cables. In addition, this part is also provided with a heat sink to ensure that the temperature will not be so high to burn the unit.

The traction structure. The cable can be made by lightweight nylon. One end is connected with the output of wind power generation device and the solar power generation unit, the other is with the control storage portion to ground. The cable in the selection must have high strength, low resistance and low density. When the power is transmitted to ground, electric energy can be stored by the battery.

When the wind is heavy, the structure can exert a force of containment in order to limit the movement of the device. Meanwhile, the device also has additional fixing ring, one end of which is fixed inside the shell, the other is connected with the traction portion, which can be rotated at 360 degree.

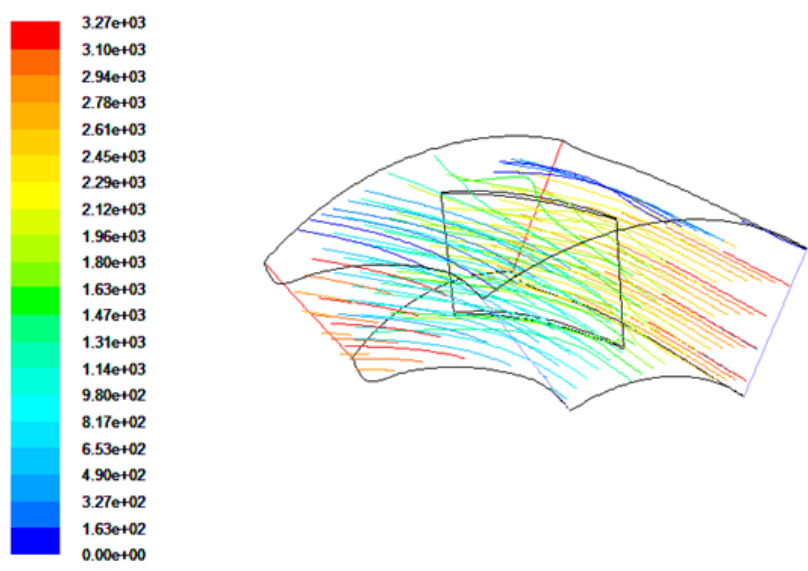

Fig. 3 Schematic diagram of streamline

\section{Simulation.}

The simulated object for axial-flow wind turbine is its inner flow field. In order to make full use of wind resources in the sky, the device is flied to the altitude of 300 meters, so the corresponding inlet pressure is $97.33 \mathrm{kPa}$ and wind speed is approximate to $12 \mathrm{~m} / \mathrm{s}$. 
Figure 3 shows the distribution of streamline in the inner flow passage. As can be seen from the graph, in every section of the flow field, the streamline's distribution is uniform and the streamline is smooth, so the air flow can be considered stable, and there's no significant impact of the air flow in the whole flow field, which is of great help to improve the use of generator.

\section{Summary}

Through the above analysis, this design has the following advantages:

The airbag structure can be sent to the higher level of the sky to make full use of wind and solar energy, which make it possible to overcome the height restrictions. It can also conduct flexible height adjustment for better power effect according to the height of each wind energy.

The addition of the the overspeed limitor and cooling device can avoid the generator working at high temperature to prolong its life.

Spiral blade structure may make the blades reduce the resistance, the degree of blade friction and heat generation, improving the conversion efficiency of wind power.

The combination with wind and solar power can be both clean and renewable, which is in line with the concept of environmental protection.

\section{Reference}

[1].Chen Fumin,High-altitude wind power-a new energy revolution[J].ZHONGDENG ZHIYE JIAOYU,2010(10).

[2]. Roberts Bryan W, Pan Zaiping. A new means of generating electricity using upper atmospheric winds [J].Acta Energiae Solaris Sinica, 1999.

[3]. Ho R H S.Lateral Stability and Control of a Flying Wind Generator [D].Sydney: University of Sydney, 1992.

[4]. Irving Granet. Fluid Mechanics for Engineering Technology [M].Prentice-Hall Inc, 1981.

[5]. Han Zhanzhong, Wang Jing, LAN Xiaoping. FLUENT Fluid Engineering Simulation Calculation Example and its Application [M].Beijing: Beijing Institute of Technology press, 2004. 